Article

\title{
Evolutionary Assessment of the Ecological Governance under the Metropolitan Background: Evidence from Chongming Eco-Island, Shanghai, China
}

\author{
Rong Sheng ${ }^{1,2}$ and Tuo Lin 1,3,* \\ 1 Institute of Eco-Chongming, East China Normal University, Shanghai 200062, China; shengrong5@126.com \\ 2 Institute of Urban Development, East China Normal University, Shanghai 200062, China \\ 3 School of Urban \& Regional Science, Institute of China Administrative Division, East China Normal \\ University, Shanghai 200062, China \\ * Correspondence: tlin@re.ecnu.edu.cn
}

Received: 8 August 2019; Accepted: 9 September 2019; Published: 26 September 2019

\begin{abstract}
Just as its general theoretical foundation does, the quantitative evaluation of ecological governance does not have a sound research compilation. This study aims to construct the ecological governance evaluation model and determine the indicator weights, premised on quantitative methods. The evaluation model is expected to embody the new features of the contemporary ecological governance, especially the metropolitan background and regional functions. Given the previous studies and conceptualizations, it is proposed based on (1) fundamental socio-economic development, (2) ecological environment quality, (3) ecological governance and innovation, and (4) regional interconnected functions. The model covers multiple index layers and various indicators, and the entropy weight method is applied to obtain the weights. The results of the specific case in Chongming show the indicator of the number of beds for old-age nursing homes in urban and rural areas, the area of real afforestation, the number of approvals in the project environmental assessment and the freight volume have the biggest weights in each of the four aspects respectively. The level of ecological governance in Chongming Island has been continuously improving, especially in 2015 and 2016, with increases doubling or tripling those of the previous two years. The index values of the four aspects generally showed an upward trend. The comprehensive social economic level and the regional interconnected level continue to grow. The levels of ecological environment quality and the ecological governance and innovation fluctuated in 2013 and 2014, but returned to growth in 2015, and increased significantly in 2016.
\end{abstract}

Keywords: evaluation model; ecological governance; metropolitan; Chongming; Eco-island

\section{Introduction}

The industrial and technological revolutions have brought great changes in social and economic activities. People have become more capable of knowing, communicating with, and even manipulating nature. However, this is often by way of sacrificing agreeable ecological and environmental conditions. This, in turn, has prompted people to think and deal with these problems by means of ecological governance. The contemporary ecological governance advance is unfolded against the background of metropolitan expansion. The changing socio-ecological conditions of a certain geo sphere are intertwined with the characteristics and trends of the metropolises in which it is located. 


\subsection{Ecological Governance under the Metropolitan Background}

The academic debates on ecological governance in the contemporary era can be seen as originating from two specific fields. One is environmental governance. As environmental problems draw great attention from the public and academia, the existing environmental governance regimes serve to deal with the environmental issues. But unfortunately, environmental governance has not reached a consensus on a unified theoretical foundation [1,2]. Even the major research fields included in the environmental governance are still in the explorative stages, which reveals that environmental governance is in strong need of practical application. The environmental governance focuses on some environmental elements, such as water, air and natural resources, while ecological governance goes into the interdependent structures and functions from politics and economy, far beyond the natural and habitat issues [3]. This leads to the explanation of the second academic source, namely the adaptive governance. The relevant studies on social dimensions arose as the supplements to the environmental governance in the so-called ever-changing social-ecological systems. Given the social and ecological conditions, some researchers have asserted that adaptive governance (AG) should be examined in terms of structures and processes [4-7]. AG leads us towards a flexible form to confront the rapid ecological changes and also makes the social dimension prominent. It serves as an alternative to previous environmental control and the optimal use of resources, especially when facing the instability characterized by abrupt crisis and dramatic turbulence [6]. What ecological governance has in common with adaptive governance lies in the shared responsibilities of realizing social and economic goals, in addition to the environmental ones.

The metropolitan context provides a new background and spatial perspective of the current ecological governance. Therefore, ecological governance has experienced two rounds of upgrading. One is the inclusion of social insights when confronting environmental challenges. The other is the spatial extension to the regional sphere, especially the metropolitan regions. As we may say, the perceivable environmental and social issues are those of the inevitable consequences of metropolitan sprawl in modern society. In the United States, for example, the number of metropolitan areas increased from 169 to 347 between 1950 and 2000, causing not only direct harmful impact on environmental elements such as air and water etc., but also on public facility provision and residents' emotional status as well [8]. It is also though that urban sprawl partly accounts for landscape degradation in regional areas [9]. The same trend also applies to the situation in China, during the massive urbanization process. These facts mean that the metropolitan sprawl has been a basic pre-condition of most governance activities. Wherever someone is based, one is never far from the metropolis. It seems impossible to escape from metropolitan areas [10]. Furthermore, any public administration or private operation is all constrained by this fact. Ecological governance is no exception.

Another consideration of locating the ecological issues within the metropolitan range lies in the public attributes of most environmental facilities and ecological services. There are many cases in which the environmental issues are dealt with in the metropolitan regions, especially in the domains of watersheds, wetland restorations, green space system, and so on. For example, in the New York City Metropolitan Area, which is characteristic of metropolitan areas in North America, a network of green space systems is proposed, based on 11 diversified regional reserves and existing urban green spaces [11]. The ecological governance behaviors typically are carried out in the regional sphere instead of a certain city range. This is because the water, wetland or green space commonly stretches beyond the city. The larger regions are often connected by the water, wetland or green space systems in the ecological sense. Therefore, they have some certain self-organizing features of the ecological systems, to some extent.

\subsection{From the Sustainability Evaluation to the Ecological Governance Evaluation}

Evaluating the level and process constitutes one of the critical parts of ecological governance. When elaborating the evaluation of ecological governance, we may draw on the experiences from sustainability evaluations and indicators. Sustainability is, in itself, a complex term encompassing 
multiple goals including those of environment, economy and society. It resembles ecological governance in covering both environmental and social-economic conditions. This is why we start from the sustainability measurement to understand the ecological governance evaluation. The sustainability measurement is an important part in academic inquiry of ecological economics. Since sustainable development has been conceptualized, indicators are developed to conduct empirical research from multiple perspectives in the three pillars of sustainability, namely environment, economy and social development [12-17]. The Human Development Index (HDI) by the United Nations Development Program (UNDP) is premised on three basic aspects of expected life span, education and living quality. Some researchers use HDI to see how sustainability functions in the ecological field $[18,19]$. Another noticeable category of the indicators concerns the ecological footprint. The concept of ecological footprint originated in the 1990s. Rees and Wackernagel tried to measure the relations between humans' claiming of natural resources and the earth bearing capacity [20]. Some researchers further lead us to understand how sustainability indicators will enter the policy domain and governance process [21,22]. Hezri and Dover discuss how sustainability indicators are resonant with decision-making, given a certain governance system [21]. Asserting that sustainability indicators often facilitate the policy process in an indirect and soft way, Sébastien and Bauler suggest that the receptivity of the indicator development is crucial for involving various actors and the general political contexts [22]. However, what makes the ecological governance evaluation differ from the sustainability measurement is that the latter often does not embody the actions and process taken to combat the ecological problems. More sustainability relevant indicators may vary in their research themes. For example, some researchers have proposed to consider the stakeholders' perspectives in the city branding evaluation steered to sustainable urban development [23]. A sustainable development assessment is constituted of the economic and environment indicators that are characteristic of deriving from public participation and consultation, including local academics, government officers of Shanghai and Chongming, community, farmers and workers etc., [24]. Some researchers, from the perspective of bio-economy, have set a framework focusing on the intersections of the three pillars of the sustainability, namely environment, economy and society [25], but which lacks the governance dimension in sustainable development. Some researchers have pointed out the necessity to build the sustainability assessment from regional perspectives, but have not specified the metropolitan level in the detailed indicators and applications [26]. Well-being is also a theme extended from sustainability goals and regarded as an objective of the assessment [27]. But all these could be drawn upon to contribute to the evaluation model under construction in this research.

Ecological governance is increasingly becoming an attractive research field and has undergone rapid development in recent years. Unfortunately, just as its general theoretical foundation does, the quantitative evaluation of ecological governance does not have a sound research compilation. It still requires further research efforts to reflect the characteristics of the above stated environmental, social-ecological, governance and metropolitan background. Therefore, this study aims to construct the ecological governance evaluation model and determine the index weights premised on the quantitative methods. It differs from the previous sustainability evaluations and indicators, because it is an integrated construction of an ecological governance evaluation model and particularly includes the governance dimension under the metropolitan background at a larger range. The evaluation model is expected to embody the above new features of contemporary ecological governance.

It selects Chongming Eco-island in Shanghai as the case to construct and apply the evaluation model. In China, the latest development in Chongming is closely related to metropolitan extension. Under the goal of an Eco-island, Chongming is trying to develop a green and high tech trans-industrial system, while strengthening the green land and ecological water environment in the Shanghai metropolis. Meanwhile, it is also undertaking the bigger role of linking the regional development in Yangtze River Delta, especially between Shanghai and Jiangsu province. The United Nations Environment Planning Program (UNEP) carried out an investigation on the ecological development in Chongming in July, 2014. The evaluation results revealed that the Chongming eco-development 
embodied the green economy concept of UNEP and served as a classical case [28]. Therefore, the constructing and application based on Chongming is of classical representative meaning in the ecological governance evaluation under the metropolitan background.

The existing evaluations on Chongming include those on ecosystem service value, eco-security, low carbon balance, wetland ecosystem health status, reduction of chemical pesticides and chemical fertilizers. Researchers made investigations of changes in land use and ecosystem services on Dongtan between 1990 and 2000, showing the total value of ecosystem services in Dongtan declining by $62 \%$ from $\$ 316.77$ to 120.40 million per year between 1990 and 2000, which is largely attributable to the $71 \%$ loss of wetlands/tidal flats [29]. From the perspective of a complex system science, a compressive assessment index system and a spatial variation assessment index system for Chongming's eco-security have been established, showing that in recent years the comprehensive score of eco-security has been gradually rising [30]. Some propose an integrated methodology centered on a carbon neutral coefficient $(\mathrm{CNC})$ to evaluate urban sustainability within a local urbanization process from a carbon cycle perspective. The remote-sensing based analysis shows that the change of land use and cover can greatly influence the local carbon balance and sustainable development [31]. Some researchers have conducted a comprehensive and objective assessment of wetland ecosystem health conditions, based on indicators obtained from satellite imagery and current field surveys, the results of which show that more than $75 \%$ of the total study area has been at a relatively healthy level and that the ecosystem health condition has a spatial variation relative to the distributions of elevation and land cover types [32]. Some claim that existing assessments rely too heavily on technocratic indicator systems after analyzing these studies on eco-island development, and then develop a broader planning and policy-oriented assessment matrix of their own [33].

Based on the above, most papers focus on the environmental factors. There is research paying attention to the planning and policy, but this does not quantify the governance measures in Chongming. Some researches place the studies under urbanization, but this just involves some basic indicators of land use and habitat. Even in this specific case of Chongming, few extant studies embody the quantified governance and metropolitan dimensions as being integral to ecological governance.

The remainder of the paper is organized as follows. The next section constructs the ecological governance evaluation model under the metropolitan background, including the quantitative methods and data. The third section presents the evaluation results, showing how the ecological governance status of Chongming in Shanghai has evolved in five years. The fourth section proposes the policy implications and the final section provides a conclusion and suggests possible further work.

\section{Ecological Governance Evaluation Model under the Metropolitan Background}

\subsection{Construct the Evaluation Index}

The index framework includes 4 A-layer indexes, namely, comprehensive social and economic development, ecological environment quality, ecological governance and innovation, regional services and cooperation exchanges. It includes a total of 13 B-layer indexes and $44 \mathrm{C}$-layer indicators.

Specifically, the A-layer index of "comprehensive social and economic development" consists of three B-layer indexes, including population profile, economic development and comprehensive level of society.

The A-layer index of "ecological environment quality" consists of four B-layer indexes, including regional environmental quality, agricultural and forestry environmental quality, industrial environmental level, and human settlement environmental quality.

The A-layer index of "ecological governance and innovation" consists of three B-layer indexes, including ecological demonstration and promotion, environmental protection input management, and scientific and technological innovation.

The A-layer index of "regional services and cooperation exchanges" consists of three B-layer indexes, including population mobility, goods turnover and communication, and industrial cooperation. 
The specific C-layer indicators are shown in Table 1.

Table 1. The evaluation index of ecological governance.

\begin{tabular}{|c|c|c|}
\hline A-Layer Indexes & B-Layer Indexes & C-Layer Indicators \\
\hline \multirow{3}{*}{$\begin{array}{l}\text { Comprehensive } \\
\text { social and economic } \\
\text { development (A1) }\end{array}$} & Population profile (B11) & $\begin{array}{l}\text { Registered population }(\mathrm{C} 111) \\
\text { Natural population growth rate (C112) } \\
\text { Population density (C113) } \\
\text { Average life expectancy }(\mathrm{C} 114)\end{array}$ \\
\hline & Economic development (B12) & $\begin{array}{l}\text { Value added (C121) } \\
\text { Value added of the tertiary industry (C122) } \\
\text { Gross agricultural output value (C123) } \\
\text { Fiscal revenues (C124) } \\
\text { Total fixed assets investment (C125) } \\
\text { Per capita amount of social consuming goods retailing (C126) }\end{array}$ \\
\hline & $\begin{array}{l}\text { Comprehensive level of } \\
\text { society (B13) }\end{array}$ & $\begin{array}{l}\text { Per capita disposable income of urban households (C131) } \\
\text { Per capita disposable income of rural households (C132) } \\
\text { Number of new jobs/employment (C133) } \\
\text { Amount of local finance invested in education (C134) } \\
\text { Number of beds for medical and health care (C135) } \\
\text { Number of beds for old-age nursing homes in urban and } \\
\text { rural areas (C136) }\end{array}$ \\
\hline \multirow{4}{*}{$\begin{array}{l}\text { Eco-environmental } \\
\text { quality (A2) }\end{array}$} & $\begin{array}{l}\text { Regional environmental } \\
\text { quality (B21) }\end{array}$ & $\begin{array}{l}\text { Level of total suspended particles in the atmosphere (C211) } \\
\text { Water quality qualification rate of drinking water source (C212) } \\
\text { Surface water quality qualification rate (C213) } \\
\text { Regional environmental noise level (C214) }\end{array}$ \\
\hline & $\begin{array}{l}\text { Agricultural and forestry } \\
\text { environmental quality (B22) }\end{array}$ & $\begin{array}{l}\text { Area of arable land (C221) } \\
\text { Area of real afforestation (C222) } \\
\text { Amount of fertilizer applied (C223) } \\
\text { Amount of pesticide applied (C224) }\end{array}$ \\
\hline & $\begin{array}{l}\text { Industrial environmental level } \\
\text { (B23) }\end{array}$ & $\begin{array}{l}\text { Qualification rate of industrial wastewater discharge (C231) } \\
\text { Removal rate of industrial fumes and dust (C232) } \\
\text { Comprehensive treatment rate of industrial solid waste (C233) } \\
\text { Energy consumption of value-added (C234) }\end{array}$ \\
\hline & $\begin{array}{l}\text { Human settlement } \\
\text { environmental quality (B24) }\end{array}$ & $\begin{array}{l}\text { Investment in rural environmental protection (C241) } \\
\text { Investment in urban environmental infrastructure construction (C242) }\end{array}$ \\
\hline \multirow{3}{*}{$\begin{array}{l}\text { Ecological } \\
\text { governance and } \\
\text { innovation (A3) }\end{array}$} & $\begin{array}{l}\text { Ecological demonstration and } \\
\text { promotion (B31) }\end{array}$ & Number of state-level ecological demonstration sites (C311) \\
\hline & $\begin{array}{l}\text { Environmental protection } \\
\text { investment management (B32) }\end{array}$ & $\begin{array}{l}\text { Proportion of environmental protection input of the whole } \\
\text { county/district in GDP (C321) } \\
\text { Amount of local finance invested in environmental protection (C322) } \\
\text { Number of approvals in the project environmental assessment (C323) }\end{array}$ \\
\hline & $\begin{array}{l}\text { Scientific and technological } \\
\text { innovation (B33) }\end{array}$ & $\begin{array}{l}\text { Number of patent applications (A331) } \\
\text { Contract amount of technology transactions (C332) } \\
\text { Amount of local finance invested in science and technology (C333) }\end{array}$ \\
\hline \multirow{3}{*}{$\begin{array}{l}\text { Regional services } \\
\text { and cooperation } \\
\text { exchanges (A4) }\end{array}$} & Population mobility (B41) & $\begin{array}{l}\text { Population moving in within the year (C411) } \\
\text { Population moving out within the year (C412) }\end{array}$ \\
\hline & $\begin{array}{l}\text { Goods turnover and } \\
\text { communication (B42) }\end{array}$ & $\begin{array}{l}\text { Freight volume (C421) } \\
\text { Post and telecommunications revenue (C422) }\end{array}$ \\
\hline & Industrial cooperation (B43) & $\begin{array}{l}\text { Number of enterprises introduced (C431) } \\
\text { Actual paid-in foreign capital (C432) } \\
\text { Tourism revenue (C433) }\end{array}$ \\
\hline
\end{tabular}

The above index is constructed based on the following conceptualizations and existing work.

\subsubsection{Comprehensive Social and Economic Development (A1)}

As indicated from the above, ecological governance goes far beyond the natural and habitat issues [3]. Based on the features of the adaptive governance, it provides guidelines and solutions to the practical social-ecological issues [34-37]. So, the comprehensive social and economic dimension is considered in our index. It is measured from the following aspects of population, economy and society. 
1. Population profile (B11) and its C-layer indicators. The population is the most dynamic factor in the social-ecological system. It is critical to get to know the population status prior to others. The registered population (C111) and the population density (C113) present an area's basic population situation, and the natural population growth rate (C112) indicates how it is expected to evolve in the near future. The well-being of the humans is also made prominent in the social-ecological governance in some other international cases [38]. Therefore, the average life expectancy (C114) is set in our index to embody our concern for this.

2. Economic development (B12) and its C-layer indicators. Ecological governance under the metropolitan background is supposed to be premised on a certain high degree of economic level attainment, because it makes it possible to use sufficient sources to protect the bio-diversity and combat the environmental degradation. The value added (C121) and especially the value added aspect of the tertiary industry (C122), together are integrated to examine an area's economic capacity and its transformation to a greener level. The gross agricultural output value (C123) is also an important part in the economic output in that it is an indicator of food supply and safety. The fiscal revenues (C124), the total fixed assets investment (C125) and the per capita amount of social consuming goods retailing (C126) all represent whether a society is vibrant in its public facility support and economic mobility potential.

3. Comprehensive level of society (B13) and its C-layer indicators. Ecological governance requires society to be involved in the governance activities to some extent. The comprehensive social development is expected to act as an important support for it. A UNEP's evaluation in 2014 on Chongming eco-civilization also regarded social life and culture in the framework as one of the most important factors [28]. In our index, the per capita disposable income of urban households (C131) and of rural households (C132) are both included to reflect the basics of the social living standards. The number of new jobs/employment (C133) is to show whether the society system has potential unstable elements. The amount of local finance invested in education (C134), the number of beds for medical and health care (C135) and the number of beds for old-age nursing homes in urban and rural areas (C136) are directly related to the livelihood and benefits of people.

\subsubsection{Eco-Environmental Quality (A2)}

If the comprehensive social and economic development is the premise condition, the well-functioning eco-environmental system is able to reflect the basic status of ecological governance under the metropolitan background. It is indispensable to the evaluations and indicators generally aimed at sustainability. It not only covers the natural elements of the atmosphere, water and noise, but also pays attention to the agricultural, forestry, industrial and habitat environment of humans.

1. Regional environmental quality (B21) and its C-layer indicators. It focuses on the natural elements. Basic environmental factors are expected to represent the status of the ecological situation in an area, including the level of total suspended particles in the atmosphere (C211), the water quality qualification rate of drinking water sources (C212), the surface water quality qualification rate (C213) and the regional environmental noise level (C214).

2. Agricultural and forestry environmental quality (B22) and its C-layer indicators. Agriculture and forestry constitute major parts in the ecological system. Furthermore, this kind of relatively densely populated ecologically sensitive area is closed related to the livelihood of the people living in this area. The living conditions of the people there, and how they interact with nature, may impact significantly on the ecological environment. Therefore, this aspect is of significant and practical meaning in the index. It has the area of arable land (C221) and the area of real afforestation (C222) as detailed indicators. Some researchers have studied the combined reduction of chemical pesticides and chemical fertilizers based on an ecological model, leading to ecosystem integrity and low-carbon agriculture [39]. So, the amount of fertilizer applied (C223) and the amount of pesticide applied (C224) are also considered. 
3. Industrial environmental level (B23) and its C-layer indicators. The industrial activities are one of the critical contributing factors in the environmental degradation. Preventing industrial pollution is an efficient way to relieve environmental pressure. It includes corresponding indicators such as the qualification rate of industrial wastewater discharge (C231), the removal rate of industrial fumes and dust (C232) and the comprehensive treatment rate of industrial solid waste (C233). The energy consumption of value-added (C234) is added as a green GDP indicator, showing the clean economy orientation.

4. Human settlement environmental quality (B24) and its C-layer indicators. Caring for the human settlement environment is examined in aspects at the urban and rural environmental level. Two indicators of the investment in rural environmental protection (C241) and the investment in urban environmental infrastructure construction (C242) are taken into account.

\subsubsection{Ecological Governance and Innovation (A3)}

The concept of contemporary governance is illustrated by means of differentiating from modern government management. Both concepts are goal-oriented activities and relevant operating systems of rules, however, governance may involve diversified informal and non-governmental institutions besides government, and governance may not undertake legal or formally prescribed authority [40]. The government is argued to be still at the helm [41] while others may assert new governance without government [42]. Actually, ecological governance not only refers to the government's actions to protect the environment and bio-diversity, but also refers to mobilizing the market and social resources to cooperate with government. This inevitably requires innovations in technology and operating mechanisms.

1. Ecological demonstration and promotion (B31) and its C-layer indicators. Ecological demonstration is normally initiated by the government and participated in by various social members and enterprises. It is usually realized through certain procedures of application, approval and even financial grants support. It is an ideal manifestation of the so-called governance. In this index of ecological governance, it is indicated with the number of state-level ecological demonstration sites (C311).

2. Environmental protection investment management (B32) and its C-layer indicators. In ecological and environmental treatment, the government is bound to be the leading actor. The amount of resources the government inputs in this aspect directly impacts on the ecological governance level in an area. For this, we have the proportion of environmental protection input of the whole county/district in GDP (C321) and the amount of local finance invested in environmental protection (C322). The most influential measure of the government is to regulate other participants in relevant activities. For this we have the number of approvals in the project environmental assessment (C323).

3. Scientific and technological innovation (B33) and its C-layer indicators. Ecological modernization strives to obtain the win-win position of protecting the environment while sustaining society and economic development. The theory attempts to balance economic development and environmental protections, especially in developing countries such as China [43,44]. Ecological governance relies heavily on innovation, especially the technology upgrading to carry out environmental treatment and ecological restoration. Given this trend, we take into account the number of patent applications (A331), the contract amount of technology transactions (C332) and the amount of local finance invested in science and technology (C333).

\subsubsection{Regional Services and Cooperation Exchanges (A4)}

This A-layer index also shows that the regional functioning is integral to the metropolitan background. Furthermore, the more well-connected to the surrounding environment an area is, the more possible it is to mobilize the required resources to conduct ecological governance. 
1. Population mobility (B41) and its C-layer indicators. The foremost element of regional exchanges is people flow. It refers to the two-way directions of both in and out. The corresponding indicators are the population moving in within the year (C411) and the population moving out within the year (C412).

2. Goods turnover and communication (B42) and its C-layer indicators. The second element is the goods and information. The former is expressed with the freight volume (C421), and the latter is with the post and telecommunications revenue (C422).

3. Industrial cooperation (B43) and its C-layer indicators. Last but not least, industrial activities are indispensable to the regional exchanges. The situation of the industrial cooperation of an area with domestic and international fields is expected to greatly improve the area's ability in introducing and applying various resources including those for ecological governance. The relevant indicators are the number of enterprises introduced (C431), the actual paid-in foreign capital (C432) and the tourism revenue (C433).

\subsection{Data to Be Applied in This Case}

Based on the above evaluation framework, the required data of the C-layer indicators used are collected from Chongming socio-economic statistical reports (2013-2017), Chongming statistical year books (2013-2017), Chongming environmental status bulletins (2013-2017) and official websites, etc. The data collection periods are from 2012-2016.

From 2000 to 2005, the Chongming Eco-island began to be constructed. Its development and corresponding statistical work were in the initial stages. Therefore, the data involved in relevant ecological fields are not complete enough. From 2005 to 2010, Chongming had a major adjustment of its administrative division. Changxing island and Hengsha island were then zoned in Chongming's jurisdiction. That is to say, the basic statistical range of Chongming had changed. The data consistency in these five years has therefore been broken. As a result, the data from 2012 to 2016 have been chosen to assess the ecological governance in Chongming in this specific paper. This five-year period is characteristic of various kinds of data, which are stable and consistent, especially those in ecological and environmental governance as well as the regional coordination functions.

Though is it difficult to include all of the ecological endeavors from the dawn of the new century in this specific quantitative model of the paper, some information provided below is expected to help us know more about how Chongming's ecological construction has evolved in this relatively longer period. It will also act as a supplement to the quantitative evaluation frame in this research. As early as May 2001, it was explicitly designed in the Shanghai Urban Master Plan, that Chongming Island was to be built into an ecological island, and serve as an important mission in improving the overall ecological environment quality of Shanghai. The whole county formally embarked on an exploration of Eco-island construction. In 2005, the Chongming Three Islands Master Plan (Chongming County Regional Master Plan) 2005-2020 issued by the Municipal Government, clearly put forward the overall positioning of building a modern comprehensive ecological island. In January 2010, the Shanghai Municipal Government announced the newly formulated Chongming Eco-island Construction Program (2010-2020), which proposed the promotion of the coordinated development of resources, environment, industry, infrastructure and social services in accordance with the overall goal of building a world-class ecological island, under the guidance of a scientific index evaluation system, and further highlighted the position of ecological protection and environmental construction. Since Chongming put forward the goal of constructing the ecological island in the dawn of the new century, the frame of ecological environment governance in Chongming has gradually been shaped. With the joint efforts of the government, market, international organizations and institutions, as well as the public and the media, Chongming has invested much in ecological governance, and has had some ecological demonstration cases. It has begun to increasingly value environmental assessment in the project launching approval process. Ecological governance not only covers the original ecological conservation, but also promotes the scientific and technological innovation in the ecological construction by means of creating some 
innovation platforms, such as creator base of Changxing Marine Hi-Tech Port, the ecological agricultural science and technology innovation platform in the agricultural park, the cultural and entrepreneurial industry incubation zone in the industrial park, the creator base of Fusheng Industrial Park, and the incubator of Smart Island project.

\subsection{Entropy Weight Method}

Above all, given the different dimensions, all of the above C-layer indicators are to be normalized, premised on the data and assessment method as follows:

$$
\begin{gathered}
X_{i j}^{*}=\frac{X_{i j}-X_{i j \min }}{X_{i j \max }-X_{i j \min }} \\
(i=1,2, \ldots, \mathrm{n} ; j=1,2, \ldots, \mathrm{m})
\end{gathered}
$$

where $X_{i j}^{*}$ is the normalized value of the system $i$ with the indicator $j . X_{i j \max }$ represents the maximum value of the system $i$ with the indicator $j$. $X_{i j m i n}$ represents the minimum value the system $i$ with the indicator $j$, and $X_{i j}^{*} \in[0,1]$.

Then we need to determine the weights of the indicators. The entropy weight method is applied in the following steps.

$$
\begin{gathered}
p_{i j}=X_{i j}^{*} / \sum_{i=1}^{n} X_{i j}^{*} \\
E_{j}=-\ln (n)^{-1} \sum_{i=1}^{n} p_{i j} \ln p_{i j} \\
(i=1,2, \ldots, \mathrm{n} ; j=1,2, \ldots, \mathrm{m}) \\
W_{j}=1-E_{j} / m-\sum E_{j} \\
(j=1,2, \ldots, \mathrm{m})
\end{gathered}
$$

Among them, $p_{i j}$ denotes the contributing level of system $i$ under indicator $j$. If $p_{i j}$ equals zero, then let $\lim p_{i j} \ln p_{i j}=0 . E_{j}$ denote the entropy value of indicator $j$ and $W_{j}$ denote the entropy weight of indicator $j$.

From the above weight results in Table 2, we can see that in each of the four A-layer index there are some indicators with relatively bigger weights, meaning in each of the four aspects these indicators matter more in evaluating the respective level. In the comprehensive social and economic development (A1), the indicator of the number of beds for old-age nursing homes in urban and rural areas (C136) has the greatest weight, followed by the gross agricultural output value (C123). In the eco-environmental quality (A2), the area of real afforestation (C222) and the amount of pesticide applied (C224) occupies the first and second places in weights ranking. In ecological governance and innovation (A3), the number of approvals in the project environmental assessment (C323) is the most important weight, and the amount of local finance invested in environmental protection (C322) is second. In the regional services and cooperation exchanges (A4), the indicator with the greatest weight is the freight volume (C421). The population moving in within the year (C411) and the tourism revenue (C433) follow closely behind. 
Table 2. The entropy weight of indicators.

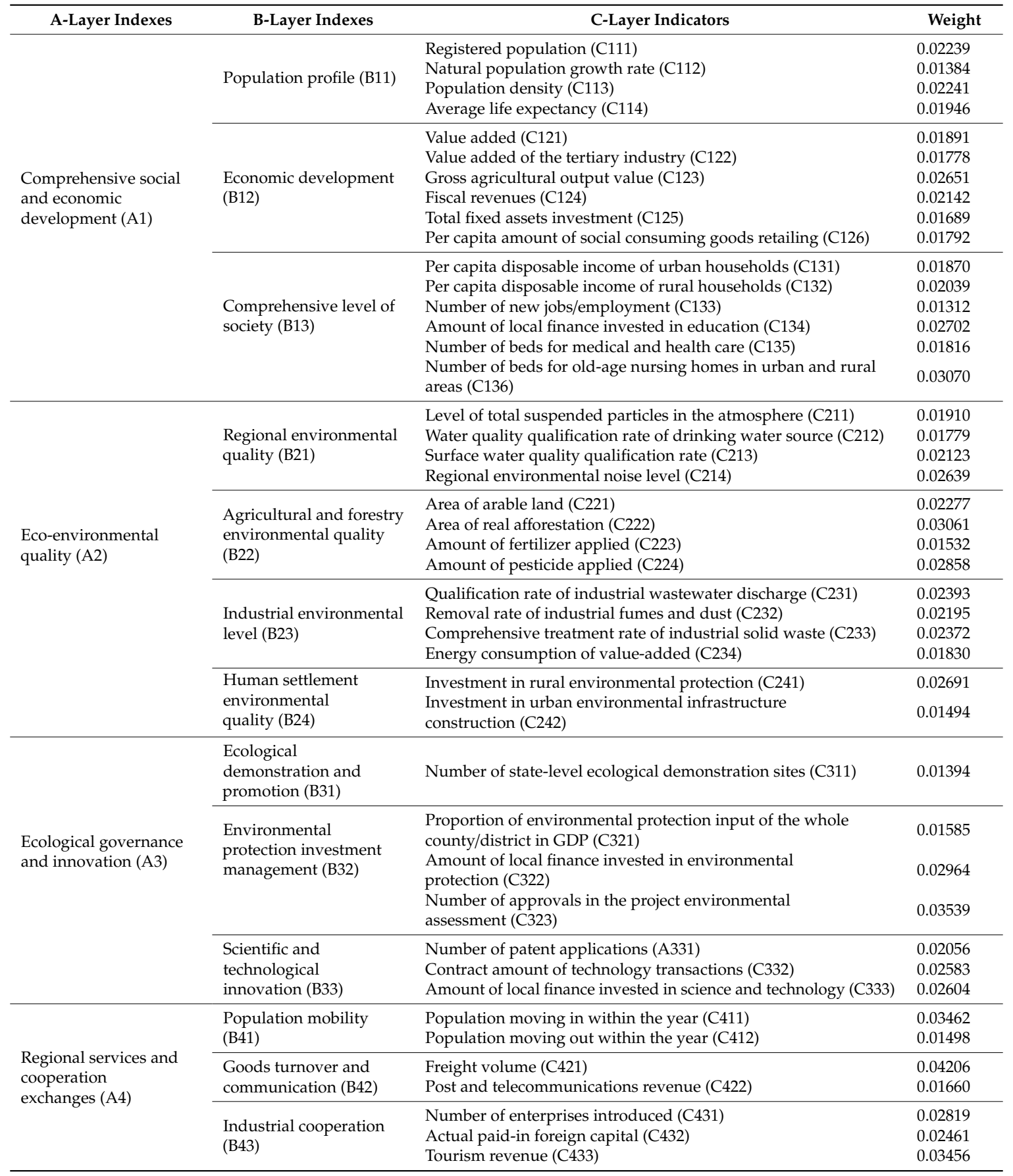

\subsection{Evaluation Model of the Ecological Governance under Metropolitan Background}

Based on the above index and weights, we construct the evaluation model of ecological governance under metropolitan background. If the model is used to evaluate an area's ecological governance situation, then the above-mentioned data will be collected to obtain the weight based on the intrinsic data information of the index construction. The scores of the various layers' index and indicators are calculated:

$$
\begin{gathered}
S_{h}^{k}=\sum_{j=1}^{m} W_{j}^{k+1} X_{j}^{k+1} \\
(\mathrm{k}=2 ; \mathrm{h}=1,2,3 \ldots, \mathrm{n} ; \mathrm{j}=1,2,3, \ldots, \mathrm{m})
\end{gathered}
$$


where $S_{h}^{k}$ denotes the score of the index $h$ in B-layers with the corresponding indicator $j$ in C-layers (actually the third layer in the index construction), $X_{j}$ is the normalized data value of indicator $j$ and $W_{j}$ is the weight of indicator $j$.

Then the scores of the index in the A-layers are obtained by summing up the scores of its corresponding B-layers. Finally, we get the result of evaluating ecological governance under metropolitan background as follows:

$$
E G=\sum_{h=1}^{4} S_{h}^{1} * 100 \%
$$

In the first layer (A-layer) there are four indexes which will be summed up to get the final evaluation results of ecological governance in our model.

\section{Application in Chongming Case and Discussion}

The results of the evaluation model application show that between 2012-2016, the values of the comprehensive assessment index were $0.19,0.29,0.36,0.54$ and 0.79 respectively. The year-on-year increase from 2013 to 2016 were $0.1,0.07,0.18$ and 0.25 respectively, indicating that the level of ecological governance in Chongming Island has been continuously improving, especially in 2015 and 2016, with increases doubled or tripled those of the previous two years.

Generally speaking, the 4 A-layer indexes showed an upward trend. It is worth noting that the level of ecological environment quality and ecological governance and innovation fluctuated in 2013 and 2014, but returned growth in 2015, and then this increased significantly in 2016. These two indexes both reached their largest growth range in 2016, which were 0.085 and 0.058 respectively (refer to Table 3).

Specifically, from 2012 to 2016, the comprehensive socio-economic development index grew continuously. The largest growth range occurred in 2013, increasing by 0.072 , compared with 2012, and was two to three times that of other years. The ecological environmental quality index fluctuated, with a negative growth of 0.037 in 2013, compared with 2012. However, it continued to increase from 2014 to 2016, with the largest growth range of 0.085 in 2016. The index of ecological governance and innovation fluctuated slightly, with a decrease of 0.002 in 2014 compared with 2013. It began to rise again in 2015 and showed the largest increase of 0.058 in 2016. The index of regional services and cooperation exchanges continued to grow, with the largest increase occurring in 2016, when it increased by 0.068 compared with 2015, (seen in Figure 1). 
Table 3. Results of the comprehensive assessment index and the A-layer indexes.

\begin{tabular}{|c|c|c|c|c|c|c|c|c|c|c|}
\hline \multirow[b]{2}{*}{ Yr } & \multicolumn{2}{|c|}{ Comprehensive Index } & \multicolumn{8}{|c|}{ A-Layer Indexes } \\
\hline & Comprehensive & Growth & $\begin{array}{l}\text { Society and } \\
\text { Economy }\end{array}$ & Growth & Eco-Environment & Growth & $\begin{array}{c}\text { Governance } \\
\text { and Innovation }\end{array}$ & Growth & $\begin{array}{c}\text { Regional } \\
\text { Service }\end{array}$ & Growth \\
\hline 12 & 0.19 & 一 & 0.059 & - & 0.099 & 一 & 0.025 & 一 & 0.007 & 一 \\
\hline 13 & 0.29 & 0.1 & 0.131 & 0.072 & 0.062 & -0.037 & 0.066 & 0.041 & 0.031 & 0.024 \\
\hline 14 & 0.36 & 0.07 & 0.152 & 0.021 & 0.085 & 0.023 & 0.064 & -0.002 & 0.054 & 0.023 \\
\hline 15 & 0.54 & 0.18 & 0.193 & 0.041 & 0.151 & 0.066 & 0.077 & 0.013 & 0.121 & 0.067 \\
\hline 16 & 0.79 & 0.25 & 0.229 & 0.036 & 0.236 & 0.085 & 0.135 & 0.058 & 0.189 & 0.068 \\
\hline
\end{tabular}

Notes: the above details are from the assessing results.

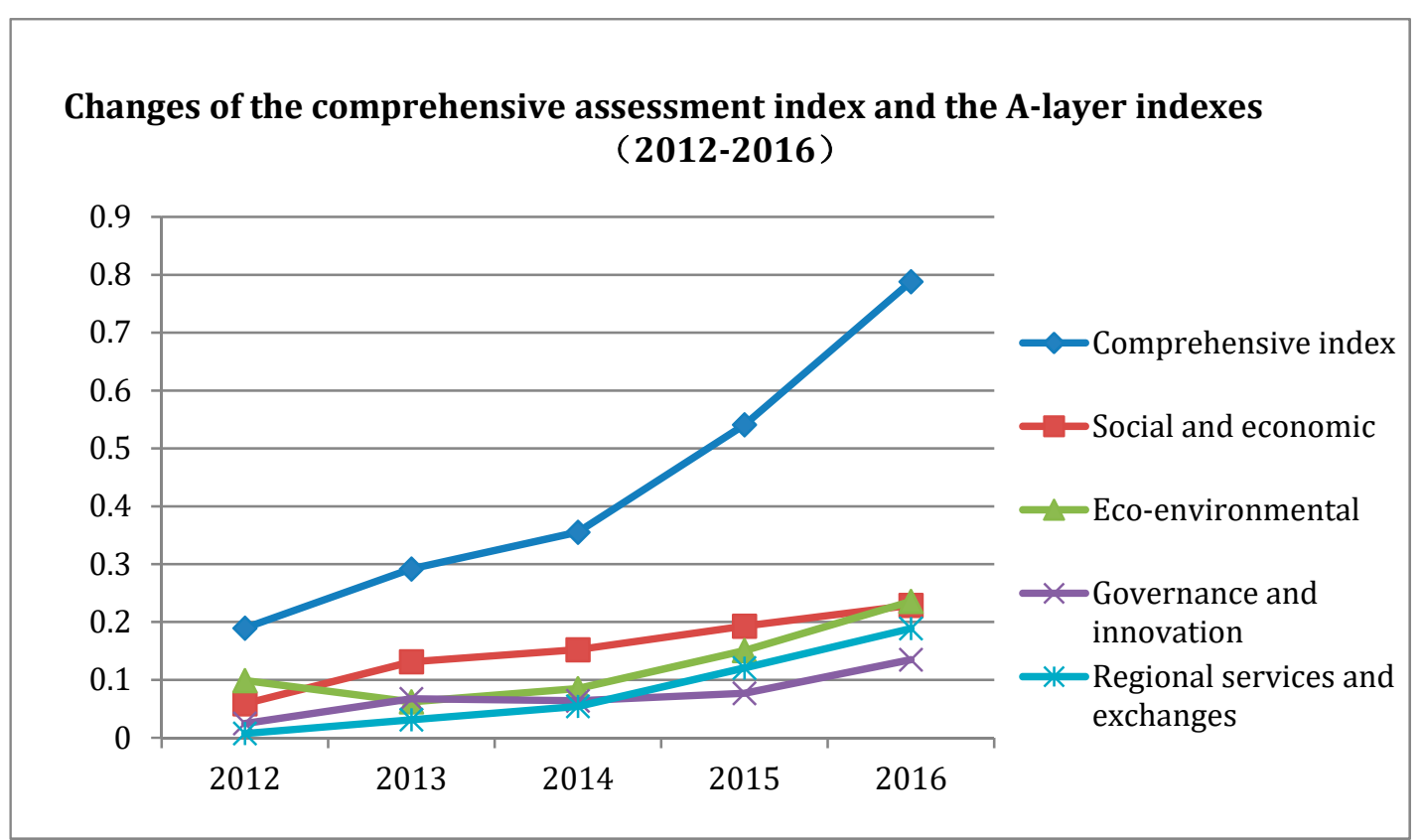

Figure 1. Changes of the comprehensive assessment index and the A-layer indexes (2012-2016) Notes: The data are from the results of the indexes evaluation. 
There is something noticeable, that in 2013, when the index of comprehensive socio-economic development reached its peak growth range in the five years, it coincided with the only negative growth in the ecological environment quality index. When the index of comprehensive socio-economic development maintained a moderate increase, the ecological environment quality index also had a certain degree of growth.

In addition, the reasons for the "low ebb" in the environmental quality in 2013 were partly from the influence of the regional and national environmental conditions. Due to the fluidity and spillover of basic environmental factors such as water and atmosphere, the overall level of the ecological environment was not only the result of local conditions, but might also have been affected by the surrounding areas. In 2013, there was a nationwide outbreak of fog and haze, especially in the Beijing-Tianjin-Hebei region. The Beijing area suffered serious air pollution. The smog affected 25 provinces and more than 100 large and medium-sized cities. The average number of smog days in China reached 29.9 days. In January 2013 alone, there were four large-scale smog periods in China, involving 30 provinces (regions and cities). The smog period with the longest duration, the widest impact and the strongest intensity occurred in most parts of the central and eastern regions [45]. In June 2013, China formulated ten measures to prevent and control atmospheric pollution, i.e., the "Ten Measures against Air Pollution", including reducing pollutant emissions, strictly controlling the new capacity of high-energy-consuming and high-polluting industries, and vigorously promoting cleaner production, which played an important role in the follow-up of the atmospheric pollution control nationwide, especially in the Beijing-Tianjin-Hebei region. In 2013, there was the incident of the Huangpu River "dead pigs" in Shanghai. More than ten thousand dead pigs were salvaged by the end of March 2013, causing wide concern across the country. In the same period, water pollution accidents occurred frequently in the Yangtze River Basin, for example, the water pollution in Yancheng City, Jiangsu in 2009, the water pollution in Zhenjiang City, Jiangsu in 2012, the 2013 Huangpu River dead pigs incident and the dead pigs incident in the Yangtze River tributary in Yichang City, Hubei, the Hanjiang River water pollution in Wuhan in 2014 affecting water consumption of 300,000 residents, and the abnormal water quality in Jingiiang River in Jiangsu [46]. From these examples, it can be seen that in 2013 there were frequent ecological and environmental crises in China. These environmental and sanitation incidents had a direct impact on people's daily lives and health. These urged us to think about how to change the policy, industry, lifestyle and whole development mode. According to the assessment results of our research, located in the Yangtze River Delta and acting as the link between Shanghai and central Jiangsu, Chongming's environmental quality factors, such as atmosphere and water environment were inevitably affected by the whole region, which also reflected the status of China's environment at that time.

In addition, the comprehensive socio-economic development and regional functions of Chongming experienced leap-forward development in 2013. Both the government's investment in environmental protection and the actual activities of the market itself were at a higher degree of vitality. The population moving-in also increased considerably. The indicators concerning the levels of the water, atmosphere, sound and other important environmental elements in 2013 and even in 2014 dropped sharply, and the industrial environmental level was also affected to some extent.

\subsection{Comprehensive Social and Economic Development}

The A-layer index of "comprehensive social and economic development" consists of three B-layer indexes, including population profile, economic development and comprehensive level of society. The changes in the five years can be seen in Figure 2. 


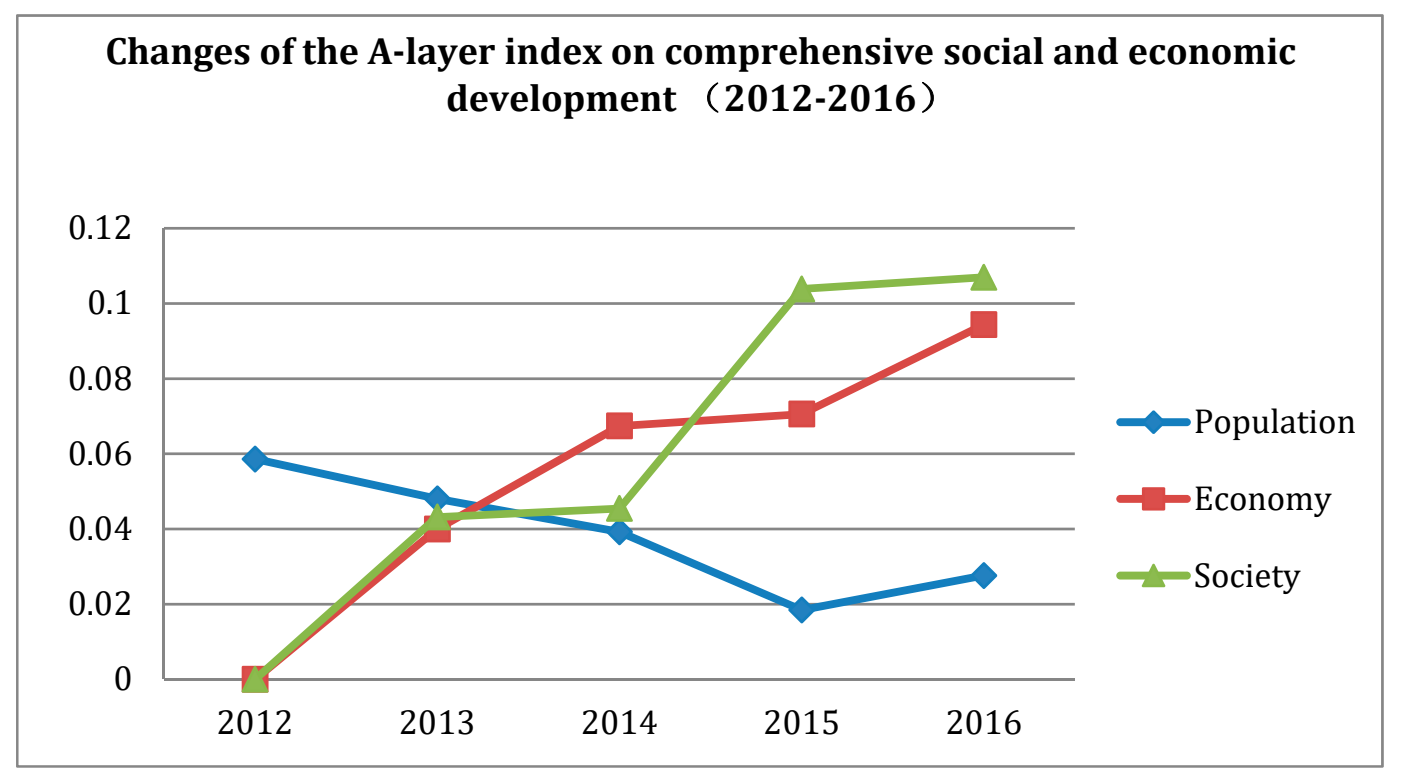

Figure 2. Changes of the A-layer index on comprehensive social and economic development (2012-2016):

The data are from the results of the indexes evaluation.

First of all, the level of the population profile index showed a downward trend from 2012 to 2016, with only a slight increase in 2016 compared with 2015, generally indicating that the population advantage of Chongming Eco-island has been declining in the five years. The registered population dropped from 685,400 in 2012 to 670,700 in 2016, suggesting an obvious contrast with the population development trend in Shanghai. The population in Shanghai grew from 23.8 million in 2012 to 24.15 million in 2016. Chongming's population density dropped from 485 people per square kilometer in 2012 to 475 people per square kilometer, while Shanghai's population density increased from 3778 people per square kilometer in 2012 to 3833 people per square kilometer in 2016. If calculated based on the built-up area, Shanghai's population density already exceeded 20,000 people per square kilometer in 2012, which reflects the effect of population agglomeration and development in the urban center of Shanghai. As a suburban county of Shanghai, Chongming's population was still flowing to the urban center. It also showed the structural adjustment of the urban system in Shanghai. Chongming Eco-Island is an important ecological base of Shanghai with a relatively low degree of large-scale development. The centralized allocation of public services in urban centers to meet the needs of population has inevitably led to population outflow in Chongming. Meanwhile the high-quality ecological environment has been preserved to the greatest extent. This is because of the optimization and adjustment of the urban system structure between the economic vitality and the supply of public services, as well as ecological environment conservation. In addition, from 2012 to 2016, the natural population growth rate of Chongming Eco-Island kept a negative growth, from $-4.1 \%$ o in 2012 to $-5.49 \%$ in 2015 , but this turned back to $-4.67 \%$ o in 2016 . The natural population growth rate reflects the trend of natural population growth constituting the basic reason for population changes in the region. With the improvement of living standards and medical care, the pace of ageing in society has been accelerated. The pressure and high cost of urban life have put young people's desires for having children in decline. Under the dual influences of the ageing population and natural population growth rate, coupled with Chongming's location at the edge of the city, there has been a strong desire of the population to move to the central city. The average life expectancy of the population was the only advantage of Chongming among the several population indicators. It grew from 80.97 in 2012 to 82.33 in 2016, reflecting the continuous improvement of the overall ecological and living environment in Chongming.

Second, the level of economic development index continued to rise from 2012 to 2016, but the growth slowed down in 2015 and 2016. Specifically, the value added increased from 23.6 billion yuan 
in 2012 to 31.2 billion yuan in 2016, maintaining an average annual growth of about 2 billion yuan. Of the eight suburbs of Shanghai (Minhang, Jiading, Baoshan, Fengxian, Songjiang, Jinshan, Qingpu and Chongming), Chongming's value added in 2016 was at the bottom, six times lower than that of Minhang District (210.1 billion yuan) which was at the top of the value added list. If viewed from the villages and towns in Chongming, the value added mainly came from Changxing Town with the contribution of the high-end strategic equipment manufacturing industry. In 2016, the value added of Changxing Town was about 7.3 billion yuan, while those of Chengqiao Town and Chenjia Town, ranking the second and the third, were 1.6 billion yuan and 1.5 billion yuan, respectively. The value added of Chongming's tertiary industrial output increased from 8.8 billion yuan in 2012 to 15.3 billion yuan in 2016, and the growth range was relatively balanced in each year. However, the value-added of Chongming's tertiary industrial output still lagged far behind that of Minhang's 106.8 billion yuan in 2016, approximately six times lower. Among the villages and towns in Chongming, Changxing Town, Chengqiao Town and Chenjia Town still had the highest value added in the tertiary industry with about 1 billion yuan, 800 million yuan and 500 million yuan, respectively. In terms of gross agricultural output value, Chongming's situation in the five years was a bit complicated. It increased from 5.87 billion yuan in 2012 to 6.24 billion yuan in 2014. But it gradually dropped to 5.89 billion yuan in 2016. Due to the accelerated process of industrial adjustment and upgrading, the proportion of agriculture in the economic structure of the more developed provinces and regions in China was declining. But Chongming has always been an important agricultural county in Shanghai. Farmers and rural issues are important in Chongming. Therefore, based on the characteristics of Chongming's own development, to include the indicator of the agricultural output value into the evaluation framework is helpful for reflecting the characteristics and reality of Chongming's ecological construction. Although the indicator fluctuated and declined between 2012 and 2016, Chongming's gross agricultural output value was the highest among the suburban districts of Shanghai, about twice that of Jinshan, ranking in second place. In respect of the fiscal revenue, Chongming increased substantially from 2012 to 2016. It was only 6.7 billion yuan in 2012, but reached 16.1 billion yuan in 2016, with a nearly doubling increase. It had an increase of about 4 billion yuan in 2016 compared with 2015. The total fixed assets investment and per capita amount of social consuming goods retailing were also on the rise. The former increased from 13.1 billion yuan in 2012 to 14 billion yuan in 2016. Its steady growth showed that Chongming's economic vitality and appeal were strengthening. The latter increased from 9428 yuan in 2012 to 15,966 yuan in 2016, reflecting the consuming ability and purchasing power of local residents have gradually increased.

Moreover, the comprehensive level of society index was also in a state of continuous improvement from 2012 to 2016, and took a big step forward in 2015, increasing from 0.045 in 2014 to 0.104 in 2015 , more than twice as much, indicating that the level of social services that Chongming Eco-island residents can enjoy has greatly improved. As an agricultural county in Shanghai, the disposable income level of farmers is one of the important indicators of the social development in the ecological island. In 2012, the per capita disposable income of Chongming rural households was 12,124 yuan, and in 2016, it exceeded 20,000 yuan. In addition, the per capita disposable income of urban households increased from 28,936 yuan in 2012 to 41,827 yuan. Generally, the per capita disposable income of residents was somewhere around 30,000 yuan, which was not a big gap compared with other suburban counties in Shanghai. In terms of new employment, the target is 9000 persons per year. From 2012 to 2016, the numbers of new employees per year all met the target, with a minimum of 9118 in 2012 and a maximum of 9553 in 2013. As for education, medical care and old-age care and other issues that people are most concerned about, according to the quantitative indicators, Chongming's investment in these fields was basically on a steady upward trend. The amount of local finance invested in education increased from 1.774 billion yuan in 2012 to 1.936 billion yuan in 2016. The number of beds for medical and health care increased from 3039 in 2012 to 3126 in 2016. The number of beds for old-age nursing homes in urban and rural areas increased from 6410 in 2012 to 8021 in 2016. Although the index level fluctuated occasionally, the quantity and quality of these key public services still lagged far behind 
those of urban areas, yet it can be seen that Chongming has constantly been investing in these areas and has gained a stable effect. The county also actively enhanced the level of education and medical care through the collectivization of school operation, medical joint venture services and other ways.

\subsection{Ecological Environment Quality}

Under the A-layer index of "ecological environment quality", there are four B-layer indexes, namely, regional environmental quality, agricultural and forestry environmental quality, industrial environmental level and human settlement environmental quality. The changes are shown in the Figure 3.

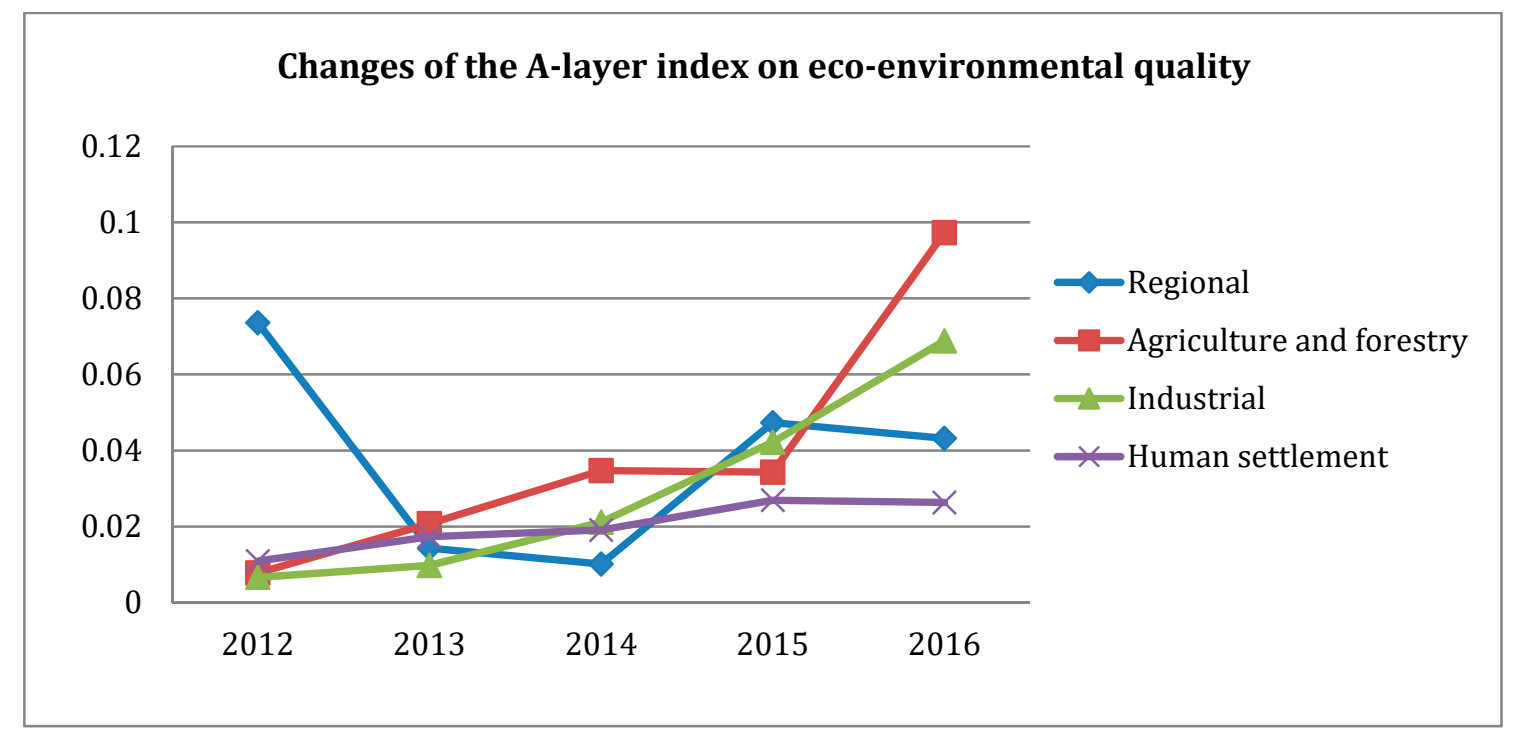

Figure 3. Changes of the A-layer index on eco-environmental quality (2012-2016) Notes: The data are from the results of the indexes evaluation.

First, the index of the regional environmental quality fluctuated significantly from 2012 to 2016, at $0.074,0.014,0.010,0.047$ and 0.043 respectively, with the highest in 2012 and the lowest in 2014. From 2012 to 2013, the index of the regional environmental quality showed the greatest decline. It can be seen from the assessment that this was one of the important reasons for the negative growth of the A-layer index of the ecological environmental quality in 2013. The C-layer indicators under the regional environmental quality index are mainly related to such basic ecological and environmental factors as air, water and noise. The daily average of total suspended particulates representing the atmospheric quality reached its highest level in 2013 , i.e., $0.14 \mathrm{mg} / \mathrm{m}^{3}$, which was more than twice the level in 2012, and gradually dropped to $0.09 \mathrm{mg} / \mathrm{m}^{3}$ by 2016 . The water quality qualification rate representing the drinking water quality was at its lowest in 2013, falling from $86.5 \%$ in 2012 to $77.8 \%$ in 2013. But the indicator value gradually rose to $98.2 \%$ in 2016 , suggesting a pick-up after the low point in 2013. The surface water qualification rate representing the quality of surface water also fluctuated obviously, dropping from $99.4 \%$ in 2012 to $97.2 \%$ in 2013, continuing to decline to $96.4 \%$ in 2014 , but rising to $99.5 \%$ in 2015 , and then falling slightly to $97.3 \%$ in 2016 . The indicator value representing the regional environmental noise level during the daytime period fluctuated slightly from 2012 to 2016, but the overall noise level was rising, indicating that the sound environment quality was on a downward trend, and it declined most in 2013. The above-mentioned regional environmental indicators representing the basic environmental factors have all been gradually improving after the crisis in 2013.

Second, the index of agricultural and forestry environmental quality in 2012-2016 was basically in an upward state, with a slight decline from 2014 to 2015. Then the level of 0.034 in 2015 increased to 0.097 in 2016, as the year with the largest increase. Specifically, the area of arable land decreased from $506.44 \mathrm{~km}^{2}$ in 2012 to $505.93 \mathrm{~km}^{2}$ in 2014, and then increased to $508.62 \mathrm{~km}^{2}$ by 2016 . The area 
of real afforestation increased significantly from 2012-2016. In 2012, the real afforestation area was 20,871 ha. Although there were slight fluctuations between the years, it increased to 28,659 ha in 2016. This reflected that the basic conditions of forestry development in Chongming Eco-island were optimized on the one hand, and on the other hand, it shows that Chongming has invested great efforts in afforestation in the past few years. The amount of fertilizer applied and the amount of pesticide applied were basically in a state of decline from 2012 to 2016, with fertilizer application reducing by about $20 \%$ by 2016 and pesticide application by about $20 \%$ by 2016 . In recent years, Chongming Eco-island has put forward the goal of "no chemical fertilizer, no chemical pesticides" in the development of eco-agriculture. It is to strictly implement the green standards of not using chemical fertilizers or pesticides in the planting process of products from rice to pear, citrus, vegetables and so on.

Third, from 2012 to 2016, the index of the industrial environmental level was in a quite clear increasing trend, and the growth range of each year was relatively significant. From 2012 to 2016, the index levels were $0.007,0.009,0.021,0.042$ and 0.069 , respectively. Specifically, in 2012, the qualification rate of industrial wastewater discharge reached $93 \%$. It gradually increased to $94.7 \%$ in 2016. In contrast, the removal rate of industrial fumes and dust experienced fluctuations in those five years, first declining from $96.12 \%$ in 2012 to $91.56 \%$ in 2013 by a large range, and then rising to $95 \%$ in 2016. The comprehensive treatment rate of industrial solid waste also decreased considerably in 2013. It then gradually increased to $95 \%$ in 2016. In addition to the above indicators, this research has also included the indicator of energy consumption of value-added, which reflects the amount of standard coal consumed per unit value added. In general, it showed a declining trend. In 2012, the energy consumption of value added was $0.41 \mathrm{t}$ of standard coal/10,000 yuan, compared with $0.37 \mathrm{t}$ of standard coal/10,000 yuan in 2016. It declined only slightly in 2015, but reached its maximum in 2016.

Finally, the index of the human settlement environmental quality continually increased from 2012 to 2016 , at $0.011,0.017,0.019,0.027$ and 0.026 , respectively, with a slight decline in 2016. Specifically, the investment in rural environmental protection was 137 million yuan in 2012, and increased steadily in 2013 and 2014. It increased to 985 million yuan in 2015, about three times the level in 2014. In 2016 it decreased to 790 million yuan. The indicator of investment in urban environmental infrastructure construction reflecting the level of urban human settlements level fluctuated greatly, rising from 1.08 billion yuan in 2012 to 1.315 billion yuan in 2013, and then gradually dropping to 770 million yuan in 2016.

\subsection{Ecological Governance and Innovation}

In the A-layer index of ecological governance and innovation, there are three B-layer indexes, namely, ecological demonstration and promotion, environmental protection investment management, and scientific and technological innovation. The evolving trend can be seen in Figure 4 as follows.

First of all, it should be mentioned that this study primarily uses the number of state-level ecological demonstration sites to represent the level of ecological demonstration and popularization. Chongming started early in this field. In 2012, there were seven state-level demonstration areas, namely, the National Wetland Ecological Demonstration Area approved by the National Forestry and Grassland Administration, the National Ecological Demonstration Area in Chongming County approved by the Ministry of Environmental Protection (the Ministry of Ecology and Environment now), the Chongming Dongtan National Nature Reserve rated by several ministries and commissions, Shanghai Chongming Yangtze River Delta National Geopark approved by the Ministry of Land and Resources (the Ministry of Natural Resources now), the National Experimental Zone for Sustainable Development approved by the Ministry of Science and Technology, the National Ecological County approved by the Ministry of Environmental Protection(the Ministry of Ecology and Environment now) and the National Wetland Park Pilot approved by the National Forestry and Grassland Administration. In 2013, the national eco-tourism demonstration area issued by the National Tourism Administration and the Ministry of Environmental Protection (the Ministry of Ecology and Environment now) approved in Chongming was 
added to the list. In 2014, it was approved in the first batch of national eco-civilization demonstration pilot zones by the six ministries and commissions led by the National Development and Reform Commission. By 2014, the number of state-level ecological demonstration sites totaled nine. From 2014 to 2016, the number stayed at nine.

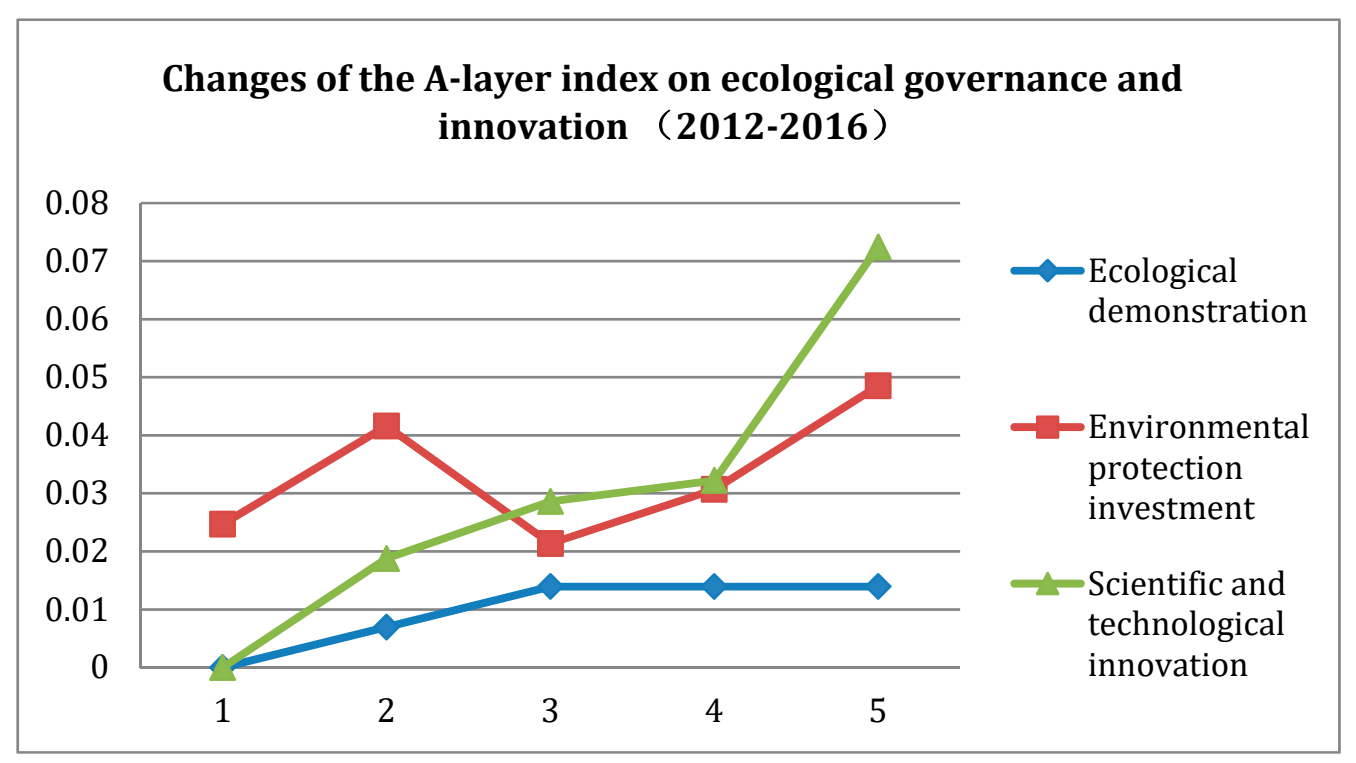

Figure 4. Changes of the A-layer index on ecological governance and innovation (2012-2016) Notes: The data are from the results of the indexes evaluation.

Second, the index of the environmental protection investment management maintained a rising trend from 2012 to 2016, at $0.025,0.042,0.021,0.031$ and 0.049 , respectively. A relatively large increase was seen in 2013, followed by a relatively sharp decline in 2014. It gradually rose after the fluctuation and was up to 0.049 in 2016. Specifically, the proportion of environmental protection input of the whole county/district in GDP increased steadily, increasing from $6.69 \%$ in 2012 to $6.94 \%$ in 2016 . The local financial investment in environmental protection also increased continuously, from 279 million yuan in 2012 to 628 million yuan in 2016. The number of approvals in the project environmental assessment has clearly fluctuated over these five years, with the highest value of 354 appearing in 2013, and the lowest value of 109 in 2015. The fluctuation of the indicator was related to the total number of projects approved, but still reflected the level of Chongming's investment level in environmental protection management to a certain extent.

Third, the index of scientific and technological innovation continued to rise from 2012 to 2016, and the growth range was relatively even from 2012 to 2015 . The index level in 2016 was 0.072 which is the highest level in these five years and more than twice the level in 2015. Of course, the level of scientific and technological innovation reflected in the relevant indicators was not entirely the result of ecology or environmental protection. However, in the period of data reflected in this study, the construction of Chongming Eco-island has been carried out for at least ten years, and the principle of ecological guidance has already been rooted in all aspects of industrial system construction and social-economic construction. Therefore, the scientific and technological innovation was centered on the ecological construction, and this study considers that it can represent the level of scientific and technological innovation in ecological governance and environmental construction. Specifically, the number of patent applications increased continuously from 45 in 2012 to 356 in 2016, indicating that Chongming's R\&D level in the fields of science, technology, knowledge or design has been continuously improving. At the same time, the awareness of property rights protection and practical action also saw improvement. The contract amount of technology transactions fluctuated significantly over the five years, with the level of 65.81 million yuan in 2012 increasing to 137 million yuan in 2013, then decreasing to 74.3 million yuan in 2015, and increasing to 214 million yuan in 2016. It reached the highest value in 2016 of the five 
years. This shows that although Chongming has experienced fluctuations in the field of technology transaction in the five years, the actual market vitality was still high. The amount of local finance invested in science and technology was on the rise, from 143 million yuan in 2012 to 353 million yuan in 2016. The level in 2016 is about 2.5 times the amount spent in 2012.

\subsection{Regional Services and Cooperation Exchanges}

Under the A-layer index of "regional services and cooperation exchanges", there are three B-layer indexes, namely population mobility, goods turnover and communication, and industrial cooperation. The changes can be seen in Figure 5.

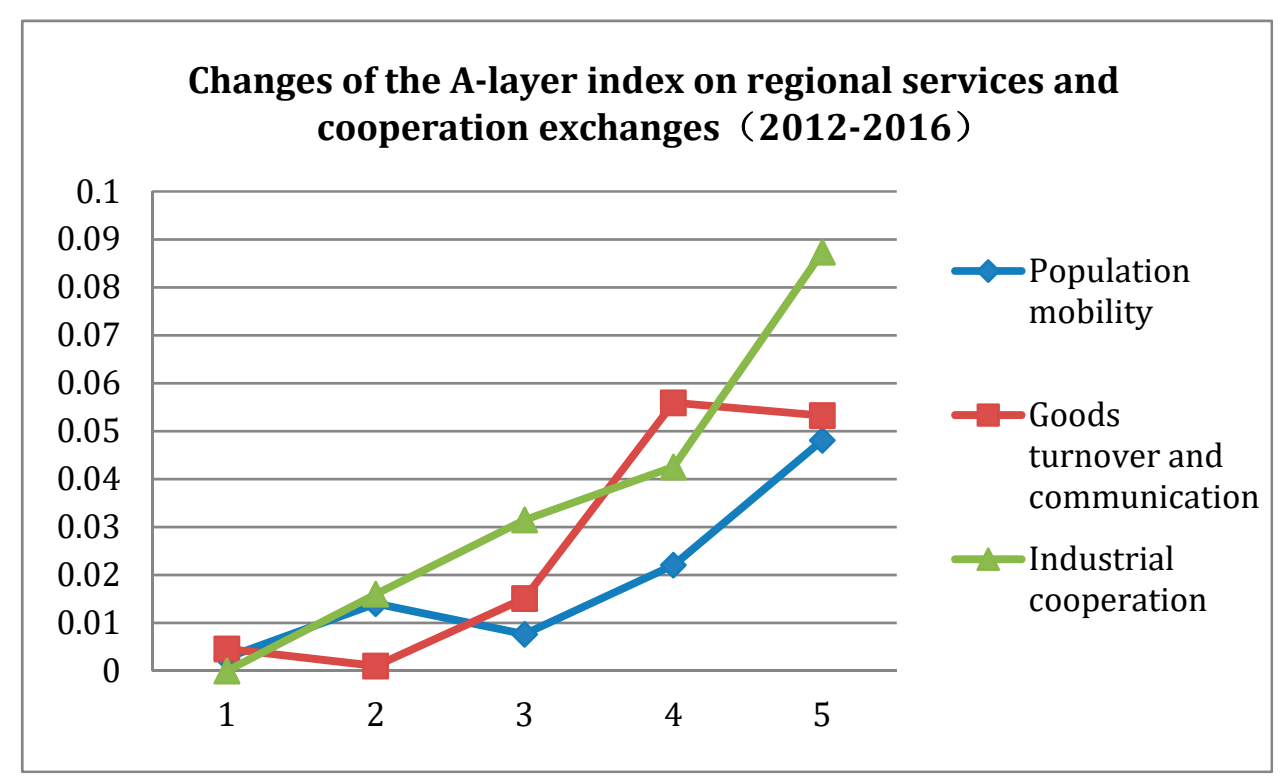

Figure 5. Changes of the A-layer index on regional services and cooperation exchanges (2012-2016) Notes: The data are from the results of the indexes evaluation.

First, the population mobility index showed a general upward trend from 2012 to 2016, at 0.003, $0.014,0.008,0.022$ and 0.048 , respectively. Only in 2013 and 2014 was there a significant fluctuation of a sharp increase and a subsequent decline, but the overall level of population mobility in Chongming was increasing exponentially. Specifically, the population moving in within the year was 5062 in 2012, and this grew to 5502 people in 2015 after some ups and downs, and increased substantially to 8316 in 2016. In contrast the population moving out within the year was basically on the rise from 2012 to 2015, with the only one decline occurring in 2016 over the five years. One of the important reasons for this phenomenon is that Chongming was made a district instead of a county in Shanghai in 2016, and it became more closely related to the development of Shanghai's metropolitan areas and became more attractive to the population, thus significantly enhancing the "siphon" effect of the urban population. In addition, it is worth noting that the two-way flow of population maintained a relatively active state in the five years, indicating that the predicament of Chongming as an "isolated island" in history has gradually gone away.

Second, from 2012 to 2016, the goods turnover and communication index maintained an upward trend in volatility, with the index levels of $0.005,0.001,0.015,0.056$ and 0.053 , respectively. The index level in 2016 was about ten times as much as in 2012. Specifically, the freight volume continued to increase, from 501.71 million tons kilometers in 2012 to 155.758 million tons kilometers in 2016, about three times as much as in 2012. The post and telecommunications revenue fluctuated over the five years, with the overall level still rising, increasing from 332.19 million yuan in 2012 to 344.52 million yuan in 2016. 
Third, the growth trend of the industrial cooperation index was easily seen from 2012 to 2016, and the growth range was relatively large. The level of the index in 2016 was 0.087 , which was more than double of that in 2015. Specifically, the number of enterprises introduced continued to increase, growing from 5290 in 2012 to 23,221 in 2016 by more than three times the level of that in 2012. The amount of actual paid-in foreign capital in general also was on the rise, increasing from $\$ 13.73$ million in 2012 to $\$ 27.86$ million in 2016, at least doubling. The tourism revenue has also maintained a state of continuous improvement over the five years, with the level of 620 million yuan in 2012 increasing to 1.09 billion yuan in 2016 by 76\%. Generally speaking, it reflects that the level of industrial cooperation in Chongming has maintained a good upward trend in the five years. Also, the tourism income not only reflected the development of emerging new industries in Chongming's ecological construction to a certain extent, but also embodied the degree of population and culture exchanges with the surrounding areas.

\section{Policy Implications}

Normally, the indicator theory and practice function as the information policy instrument in the policy making process. In other words, there exists a gap between the indicator producer and the indicator user. It refers to the influence of the indicators on the policy domain. Unfortunately, the paths by which the various indicators enter policy making are vague and are yet to be explored.

For the time being, we have several evaluation systems of the social-ecological situations that are officially in use in Chongming. There are three official editions of evaluation systems for the development of Chongming Eco-island, namely, the 23-indicator system in Chongming Eco-island Construction Program (2010-2020) issued by the Shanghai Municipal Government in 2010, the 17-indicator system in 13th Five-Year Plan for the Development of Chongming World-class Eco-island issued by the Shanghai Municipal Government in 2016, as well as the 44-indicator system of Overall Planning of Chongming District, Shanghai and Overall Planning of Land Use Planning (2017-2035) released in 2018.

In January 2010, Shanghai Municipal Government promulgated the Chongming Eco-island Construction Program (2010-2020) (hereinafter referred to as The Program). The most important feature of this plan is the formulation of the control indicator system of Chongming Eco-Island Construction. In 2009, led by the Shanghai Development and Reform Commission, Shanghai Environmental Protection Bureau, the Shanghai Municipal Agricultural Commission, Shanghai Water Authority and Chongming County Government etc. each carried out preliminary studies and formed the key 23-indicator system with an emphasis on restriction and control on the basis of the 24-indicator system in five major categories formed by the Shanghai Municipal Science and Technology Commission and the 21-indicator environmental control system formed by the Shanghai Municipal Environmental Protection Bureau. Following the key index systems of Chongming Eco-island Construction Program (2010-2020) in 2010, the 13th Five-Year Plan for the Development of Chongming World-class Eco-island put forward 17 new indexes for the construction of Chongming Eco-island. In 2018, the Shanghai Municipal Government approved the latest edition of the 44 index systems put forward in the Master Plan and General Land-Use Plan of Chongming District, Shanghai (2017-2035). So far, most of the above-mentioned indicator systems focus on the ecological and environmental factors. But an increasing number of indicators are related to society, towns and human settlements.

The above are all with limiting figures for various indicators, which are constraining characteristics for the development levels. Instead the evolutionary assessment building on an integrated framework is expected to provide an evaluation model which can show more information about the changes and trends. As some researchers have asserted, the extent complex sustainability indicators might impede the policy makers using them [47]. This framework also provides a rather clear and practical set of indicators to be applied. As some researches have discussed, the indicators from the producers need some certain policy windows to let the evaluation and indicators be taken by the policy makers [21], and the index of this research is to be tested and applied in some opportunities. 


\section{Conclusions and Further Research}

In the context of globalization, the process of urbanization has been accelerated. No single corner is left unaffected. Even the islands separated from the continent shall inevitably ride along the tide. In the design of the index system, the consideration of ecological environment quality should be based on a certain degree of social and economic development. In addition, while realizing the goal of ecological environment governance, it needs to be supported by comprehensive scientific and technological innovation, and should have certain cooperation and exchange functions to the surrounding areas. In this sense, the design of the index system is extensible and can be applied to other social and ecological development assessment.

Based on the model, this paper assessed how ecological governance evolved from 2012 to 2016 in Chongming Eco-island of Shanghai. It serves an ideal case for examining and quantifying ecological governance in the metropolitan region. The results show a general growing and evolving trend, with complicated performances among the varying dimensions, suggesting the valuable clues of the potential relational exploring between the economy and the environment. With the improving statistical techniques and sources, the data in the longer term will be applied in further research. Further detailed comparison and linkages with the global counterparts are expected in the subsequent papers to provide more clues for this research field. Survey data and corresponding analyzing methods are also expected to contribute to the subsequent research agenda. These will provide further support for ecological governance research. Another noteworthy direction might lie in the inclusion of the renewable energy efforts in the evaluation model as the reliable quantitative data collection is possible in consecutive years. Energy use, especially renewable energy use, needs the participation and support from the whole society. If not, then the whole social and ecological system will be undergoing risks. Some researchers have also involved the renewable energy in the eco-system evaluation framework [48] or focus on renewable energy as a practical goal in the renewable energy community in terms of different residential types [49]. So ecological governance under the metropolitan background can embody this important feature in the future. In this specific case of study Chongming has carried out such efforts in renewable energy, through such initiatives as renewable energy-based energy micro-grid system, distributed solar energy power generation centering on the industrial and public buildings as well as increasing the proportion of the solar, wind and biomass energy in primary energy supply. Unfortunately, these are difficult to be quantified in the evaluation model temporarily, which constitutes a limitation of this research.

It is noteworthy that application of the model in other areas may require the detailed indicators to be adjusted if there exist data collection problems. Some relevant indicators can be used to substitute certain ones and even short surveys can be used to get some data. Of course, the weights will be different in different areas. And this properly addresses the concerns for the subjective weighting and will achieve more uniqueness in local studies. This future expected method is especially necessary when including more stakeholders' perspectives, as stated above.

Author Contributions: Conceptualization, R.S. and T.L.; methodology, R.S.; formal analysis, R.S.; data curation, R.S.; writing—original draft preparation, R.S.; writing—review and editing, T.L.

Funding: This research was funded by the Fundamental Research Funds for the Central University in China, grant number 2019ECNU-HWFW017 and the major project of the National Social Science Fund of China, grant number 15ZDA032.

Conflicts of Interest: The authors declare no conflict of interest.

\section{References}

1. Young, O. Why is there no unified theory of environmental governance? In Handbook of Global Environmental Politics; Dauvergne, P., Ed.; Edward Elgar: Cheltenham, UK, 2005; pp. 170-186.

2. Economy, E. Environmental governance: The emerging economic dimension. Environ. Politics 2006, 15, 171-189. [CrossRef] 
3. Young, O.R. Environmental governance: The role of institutions in causing and confronting environmental problems. Int. Environ. Agreem. Politics Law Econ. 2003, 3, 377-393. [CrossRef]

4. Dietz, T.; Ostrom, E.; Stern, P.C. The struggle to govern the commons. Science 2003, 302, 1902-1912. [CrossRef] [PubMed]

5. Olsson, P.; Folke, C.; Hahn, T. Social ecological transformation for ecosystem management: The development of adaptive co-management of a wetland landscape in southern Sweden. Ecol. Soc. 2004, 9, 2. [CrossRef]

6. Folke, C.; Hahn, T.; Olsson, P.; Norberg, J. Adaptive governance of social-ecological systems. Annu. Rev. Environ. Resour. 2005, 30, 441-473. [CrossRef]

7. Chaffin, B.C.; Gunderson, L.H. Emergence, institutionalization and renewal: Rhythms of adaptive governance in complex social-ecological systems. Environ. Manag. 2016, 165, 81-87. [CrossRef] [PubMed]

8. Platt, R.H. Toward ecological cities: Adapting to the21st century metropolis. Environ. Sci. Policy Sustain. Dev. 2004, 46, 10-27. [CrossRef]

9. Gerard, F.; Petit, S.; Smith, G. Land cover change in Europe between 1950 and 2000 determined employing aerial photography. Prog. Phys. Geogr. 2010, 34, 183-205. [CrossRef]

10. Mumford, L. The City in History; Harcourt, Brace, \& World: New York, NY, USA, 1961.

11. Flores, A.; Pickett, S.T.; Zipperer, W.C.; Pouyat, R.V.; Pirani, R. Adopting a modern ecological view of the metropolitan landscape: The case of a greenspace system for the New York City region. Landsc. Urban Plan. 1998, 39, 295-308. [CrossRef]

12. Grzebyk, M.; Stec, M. Sustainable development in EU countries: Concept and rating of levels of development. Sustain. Dev. 2015, 23, 110-123. [CrossRef]

13. Shaker, R.R.; Zubalsky, S.L. Examining patterns of sustainability across Europe: Multivariate and spatial assessment of 25 composite indices. Int. J. Sustain. Dev. World Ecol. 2015, 22, 1-13. [CrossRef]

14. Pires, S.M.; Fidelis, T. Local sustainability indicators in Portugal: Assessing implementation and use in governance. J. Clean Prod. 2015, 86, 289-300. [CrossRef]

15. Moussiopoulos, N.; Achilla, C.; Vlachokostas, C.; Spyridi, D.; Nikoloou, K. Environmental, social and economic information management for the evaluation of sustainability in urban areas: A system of indicators for Thessaloniki, Greece. Cities 2010, 27, 377-384. [CrossRef]

16. Mayer, A.L. Strengths and weaknesses of common sustainability indices for multidimensional systems. Environ. Int. 2008, 34, 277-291. [CrossRef]

17. Hezri, A.A.; Dovers, S.R. Australia's indicator-based sustainability assessments and public policy. Aust. J. Public Adm. 2009, 68, 303-318. [CrossRef]

18. Neumayer, E. The human development index and sustainability-A constructive proposal. Ecol. Econ. 2001, 39, 101-114. [CrossRef]

19. Morse, S. For better or for worse, till the human development index do us part. Ecol. Econ. 2003, 45, $281-296$. [CrossRef]

20. Wackernagel, M.; Rees, W.E. Perceptual and structural barriers to investing in natural capital: Economics from an ecological footprint perspective. Ecol. Econ. 1997, 20, 3-24. [CrossRef]

21. Hezri, A.A.; Dovers, S.R. Sustainability indicators, policy, governance: Issues for ecological economics. Ecol. Econ. 2006, 60, 86-99. [CrossRef]

22. Sébastien, L.; Bauler, T. Use and influence of composite indicators for sustainable development at the EU-level. Ecol. Indic. 2013, 35, 3-12. [CrossRef]

23. Yang, T.; Ye, M.; Pei, P.; Shi, Y.; Pan, H. City branding evaluation as a tool for sustainable urban growth: A framework and lessons from the Yangtze River Delta Region. Sustainability 2019, 11, 4281. [CrossRef]

24. Yuan, W.; James, P.; Hodgson, K.; Hutchinson, S.M.; Shi, C. Development of sustainability indicators by communities in China: A case study of Chongming County, Shanghai. J. Environ. Manag. 2003, 68, 253-261. [CrossRef]

25. Egenolf, V.; Bringezu, S. Conceptualization of an indicator system for assessing the sustainability of the bioeconomy. Sustainability 2019, 11, 443. [CrossRef]

26. Smetana, S.; Tamasy, C.; Mathys, A.; Heinz, V. Sustainability and regions: Sustainability assessment in regional perspective. Reg. Sci. Policy Pract. 2015, 7, 163. [CrossRef]

27. Rinne, J.; Lyytimaki, J.; Kautto, P. From sustainability to well-being: Lessons learned from the use of sustainable development indicators at national and EU level. Ecol. Indic. 2013, 35, 35-42. [CrossRef] 
28. UNEP. Chongming Eco-island International Evaluation Report. 2014. Available online: http://www.unep. org/chinese/publications/pdf/chongming.pdf (accessed on 29 August 2018).

29. Zhao, B.; Kreuter, U.; Li, B.; Ma, Z.; Chen, J.; Nakagoshi, N. An ecosystem service value assessment of land-use change on Chongming Island, China. Land Use Policy 2004, 21, 139-148. [CrossRef]

30. Li, H.; Cai, Y.L. Regional Eco-Security Assessment Based on the Perspective of Complex System Science: A Case Study of Chongming in China. Hum. Ecol. Risk Assess. 2011, 17, 1210-1228. [CrossRef]

31. Guo, R.; Zhao, Y.; Shi, Y.; Li, F.T.; Hu, J.; Yang, H.Z. Low carbon development and local sustainability from a carbon balance perspective. Resour. Conserv. Recycl. 2017, 122, 270-279. [CrossRef]

32. Dai, X.Y.; Ma, J.J.; Zhang, H.; Xu, W.C. Evaluation of ecosystem health for the coastal wetlands at the Yangtze Estuary, Shanghai. Wetl. Ecol. Manag. 2013, 21, 433-445. [CrossRef]

33. Ma, X.; De Jong, M.; Den Hartog, H. Assessing the implementation of the Chongming Eco Island policy: What a broad planning evaluation framework tells more than technocratic indicator systems. J. Clean Prod. 2018, 172, 872-886. [CrossRef]

34. Huitema, D.; Mostert, E.; Egas, W.; Moellenkamp, S.; Pahl-Wostl, C.; Yalcin, R. Adaptive water governance: Assessing the institutional prescriptions of adaptive (co-) management from a governance perspective and defining a research agenda. Ecol. Soc. 2009, 14, 26. [CrossRef]

35. Clark, J.R.A.; Clarke, R. Local sustainability initiatives in English National Parks: What role for adaptive governance? Land Use Policy 2011, 28, 314-324. [CrossRef]

36. Cosens, B.; Gunderson, L.; Allen, C.; Benson, M. Identifying legal, ecological and governance obstacles, and opportunities for adapting to climate change. Sustainability 2014, 6, 2338-2356. [CrossRef]

37. Sharma-Wallace, L.; Velarde, S.J.; Wreford, A. Adaptive governance good practice: Show me the evidence! J. Environ. Manag. 2018, 222, 174-184. [CrossRef] [PubMed]

38. Parkes, M.W.; Morrison, K.E.; Bunch, M.J.; Hallstro, L.K.; Neudoerffer, R.C.; Venema, H.D.; Waltner-Toews, D. Towards integrated governance for water, health and social-ecological systems: The watershed governance prism. Glob. Environ. Chang. 2010, 20, 693-704. [CrossRef]

39. Wan, N.F.; Ji, X.Y.; Jiang, J.X.; Qiao, H.X.; Huang, K.H. A methodological approach to assess the combined reduction of chemical pesticides and chemical fertilizers for low-carbon agriculture. Ecol. Indic. 2013, 24, 344-352. [CrossRef]

40. Rosenau, J. Governance, order and change in world politics. In Governance Without Government; Rosenau, J., Czempiel, E-O., Eds.; Cambridge University Press: Cambridge, UK, 1992; pp. 1-29.

41. Pierre, J.; Peters, B.G. Governance, Politics, and the State; Macmillan: London, UK, 2000.

42. Rhodes, R.A.W. The new governance: Governing without government. Polit. Stud. 1996, 44, $652-667$. [CrossRef]

43. Mol, A.P.J. Urban environmental governance innovations in China. Curr. Opin. Environ. Sustain. 2009, 1, 96-100. [CrossRef]

44. Park, J.; Sarkis, J.; Wu, Z. Creating integrated business and environmental value within the context of China's circular economy and ecological modernization. J. Clean. Prod. 2010, 18, 1494-1501. [CrossRef]

45. The Most Serious Haze Ever in China in 2013-The Worst in 52 Years, Travel. Available online: http://travel.big5.enorth.com.cn/system/2013/12/30/011570482.shtml (accessed on 30 August 2018).

46. Jin, T.J. On China's Challenges and Western Experiences in Regional Ecological Governance. Soc. Sci. Abroad 2015, 5, 4-12.

47. Hak, T.; Janouskova, S.; Whitby, A.; Abdallah SKovanda, J. Indicator policy factsheets: A knowledge brokerage tool. Sustainability 2015, 73, 3414-3429. [CrossRef]

48. Zhan, J.; Zhang, F.; Chu, X.; Liu, W.; Zhang, Y. Ecosystem services assessment based on emergy accounting in Chongming Island, Eastern China. Ecol. Indic. 2019, 105, 464-473. [CrossRef]

49. Yang, T.; Zhang, X. Benchmarking the building energy consumption and solar energy trade-offs of residential neighborhoods on Chongming Eco-Island, China. Appl. Energy 2016, 180, 792-799. [CrossRef]

(C) 2019 by the authors. Licensee MDPI, Basel, Switzerland. This article is an open access article distributed under the terms and conditions of the Creative Commons Attribution (CC BY) license (http://creativecommons.org/licenses/by/4.0/). 